\title{
Hoarseness due to lymph node metastasis of hepatocellular carcinoma: A case report
}

\author{
LIN XU*, FENG XUE*, BOQING WANG, DONG YAN, WEI DING, JIWEI YIN, CHAO YI and WEI WANG \\ Department of Hepatopancreatobiliary Surgery, The Affiliated Tumor Hospital of Xinjiang Medical University, \\ Urumqi, Xinjiang 830011, P.R. China
}

Received April 1, 2015; Accepted May 13, 2016

DOI: $10.3892 / \mathrm{ol} .2016 .4687$

\begin{abstract}
Hepatocellular carcinoma (HCC) metastases in the mediastinum are rare, particularly under the arch of the aorta. The present study describes the case of a 30-year-old male patient who presented with back pain and hoarseness for 2 months due to lymph node metastasis of HCC. The patient had undergone right hepatic lobectomy for HCC 2 years prior and received transarterial chemoembolization 4 times following resection. A computed tomography scan revealed enlarged lymph nodes under the arch of the aorta that appeared to have invaded the left recurrent laryngeal nerve, causing the hoarseness. Percutaneous aspiration biopsy of the enlarged, right supraclavicular lymph node identified malignant cells consistent with HCC. Radiation administered as a therapy to treat for the metastatic lymph nodes did not diminish the tumor but relieved the symptoms.
\end{abstract}

\section{Introduction}

Hepatocellular carcinoma (HCC) is one of the most common types of primary cancer worldwide, with an estimated incidence of $\sim 23,000$ mortalities from liver or intrahepatic bile duct cancer (1). The primary treatment strategy for HCC is resection or liver transplantation; however, only a minority of patients present with resectable disease. Although advances in the treatment of HCC have resulted in prolonged survival of patients, the incidence of recurrence or extrahepatic metastasis associated with HCC has also risen (2). This aggressive cancer has a high recurrence rate, predominantly in the residual liver following hepatectomy. The recurrence rate following

Correspondence to: Dr Wei Ding, Department of Hepatopancreatobiliary Surgery, The Affiliated Tumor Hospital of Xinjiang Medical University, 789 Suzhou Road, Urumqi, Xinjiang 830011, P.R. China

E-mail: xlawxh1015163@163.com

${ }^{*}$ Contributed equally

Key words: hoarseness, lymph node metastasis, hepatocellular carcinoma resection is $50 \%$ at 2 years and $75 \%$ at 5 years (3). The incidence of extrahepatic recurrence of $\mathrm{HCC}$ has been reported to be $14.0-25.8 \%$ (4).Patients with extrahepatic metastasis have a poor prognosis. Current managements for these patients are oral administration of sorafenib and possibly transarterial chemoembolization for the hepatic tumors if the patient has sufficient remaining liver function (5). The most frequent metastatic sites are the lungs, lymph nodes, bones and adrenal glands (6). Metastases in the mediastinum are rare, particularly under the arch of the aorta. The present study reports the case of a patient presenting with hoarseness caused by lymph node metastasis of HCC under the arch of aorta.

\section{Case report}

A 30-year-old male patient who presented with hoarseness and back pain for 2 months was admitted to the Department of Hepatopancreatobiliary Surgery, The Affiliated Tumor Hospital of Xinjiang Medical University (Urumqi, China) in August 2014. The patient had undergone right hepatic lobectomy for HCC 2 years before (in November 2013), and received transarterial lipiodol (lipiodol plus doxorubicin and cisplatin) chemoembolization 4 times one month after the resection in The First Affiliated Hospital of Xinjiang Medical University (Urumqi, China). A medical history revealed that the patient had been diagnosed with hepatitis B 14 years prior to admission, and had been undergoing treatment with entecavir (1 tablet/day) for 2 years (since November 2011) at his local hospital. Physical examination revealed enlarged, bilateral supraclavicular masses. The level of $\alpha$-fetoprotein in the blood was elevated to $25.75 \mathrm{ng} / \mathrm{ml}$ (normal levels, $<13.40 \mathrm{ng} / \mathrm{ml}$ ), serum hepatitis B surface antigen was positive and hepatitis B virus DNA levels were 1,640 copies $/ \mathrm{ml}$ (normal range, $5 \times 10^{2}-5 \times 10^{7}$ copies $/ \mathrm{ml}$ ) (7). All other laboratory test results were normal. A computed tomography scan of the chest and upper abdomen showed intrahepatic recurrence, and multiple enlarged lymph nodes in the bilateral clavicular regions, mediastinum and peritoneum (Fig. 1). The enlarged lymph node found under the arch of the aorta was considered to have invaded the left recurrent laryngeal nerve, causing the hoarseness (Fig. 1C). Percutaneous aspiration biopsy of the enlarged, right supraclavicular lymph node identified malignant cells consistent with HCC by hematoxylin and eosin staining (Fig. 2). The multiple lymph node metastases 
A
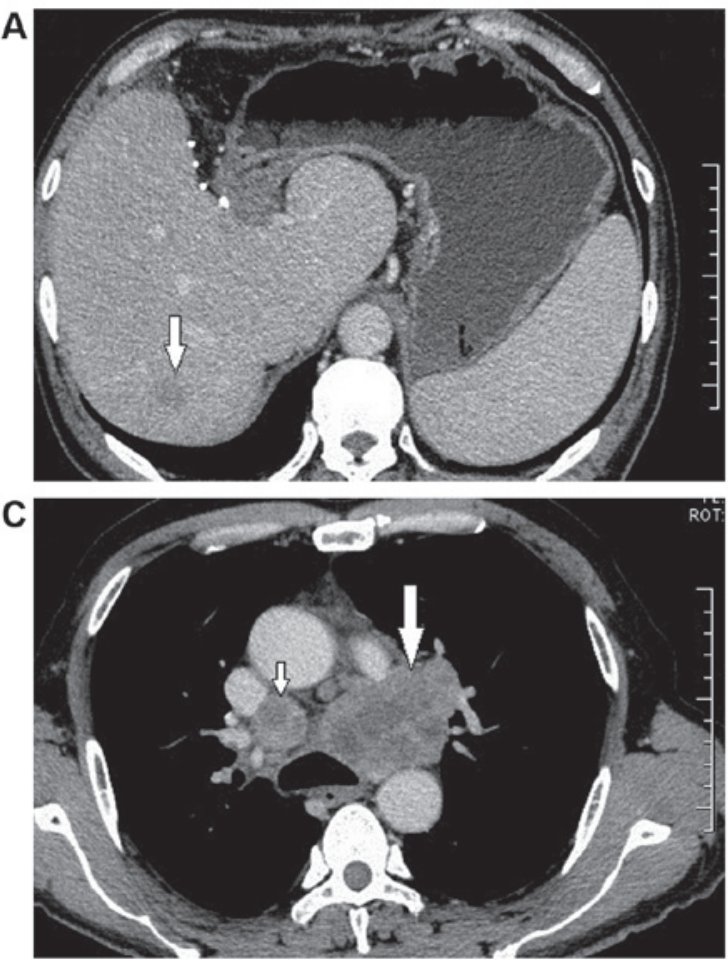
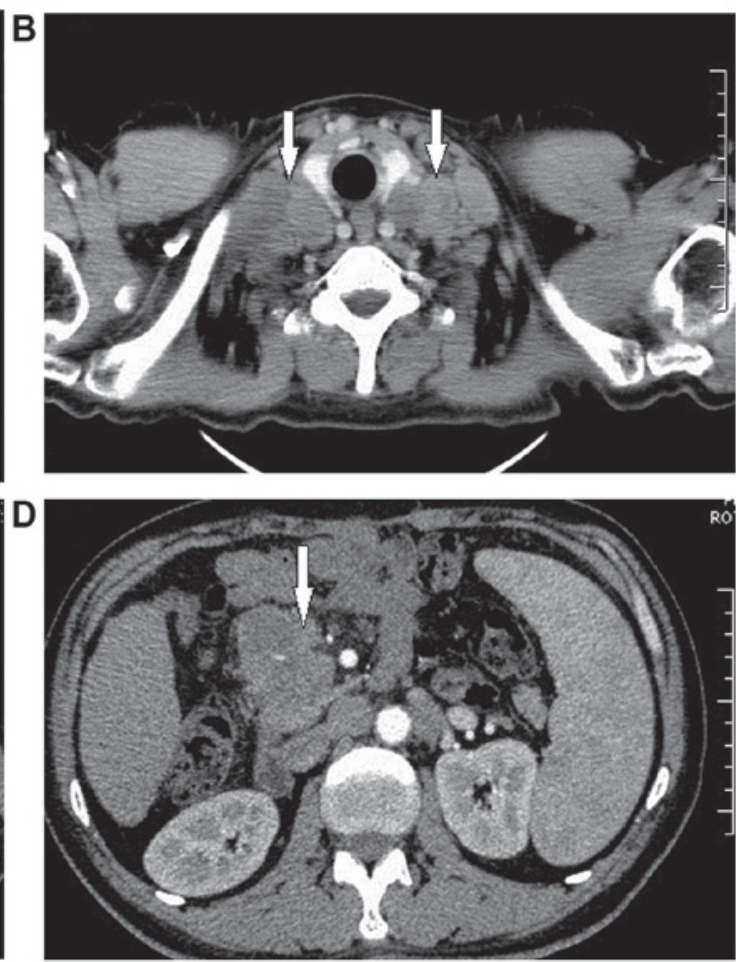

Figure 1. Abdominal and chest computed tomography scans showing abnormal masses in the liver, clavicular region, mediastinum and peritoneal lymph nodes. (A) Liver mass (arrow). (B) Multiple enlarged lymph nodes in bilateral clavicular regions (arrows). (C) Enlarged mediastinum lymph nodes (small arrow) and a particularly enlarged lymph node under the arch of the aorta (big arrow). (D) Enlarged peritoneal lymph node (arrow).

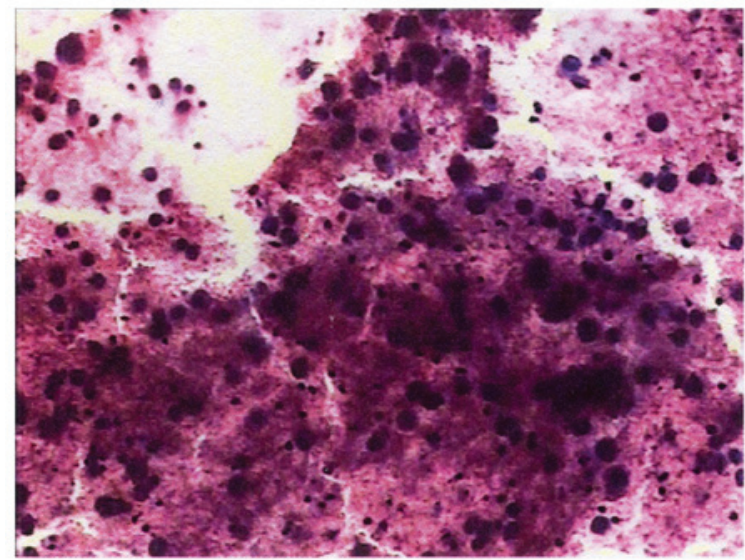

Figure 2. Histopathological examination of the enlarged, right supraclavicular lymph node revealed the presence of malignant cells (hematoxylin and eosin stain; magnification, $\mathrm{x} 400$ ).

complicated with intrahepatic recurrence were unsuitable for resection or radiofrequency ablation, but the patient was administered radiotherapy (20 Gy/10 times) in October 2013); back pain was relieved as a result. However, despite the use of recombinant human interleukin 11, the patient exhibited a decrease in platelet count from $128 \times 10^{9}$ cells $/ 1$ to $70 \times 10^{9}$ cells $/ 1$ (normal range, $125 \times 10^{9}-350 \times 10^{9}$ cells/1), which indicated radiation intolerance. The patient refused sorafenib treatment on cost grounds and was discharged from the hospital. The patient succumbed to disease 4 months after radiotherapy. Written informed consent was obtained from the patient's wife for the publication of the patient's information.

\section{Discussion}

Lymph node metastasis of HCC is closely associated with poor survival and a high risk of tumor recurrence. Although cases with mediastinal lymph node metastasis of HCC have been reported (8-11), to the best of our knowledge, the present study describes the first case of hoarseness caused by lymph node metastasis. In the present case, a pathological examination of the enlarged, right supraclavicular lymph node identified malignant cells consistent with HCC.

The treatment options for extrahepatic metastases developing after hepatic resection of HCC are limited. Regional lymph node dissection should always be performed to determine the stage of the tumor. Hepatic resection with regional lymphadenectomy is a safe procedure for patients with HCC (12), with a systematic review recommending routine lymph node dissection in patients with $\mathrm{HCC}$ at the time of resection (13). Experience suggests that a solitary lymph node metastasis from HCC can be treated surgically if there is no evidence of recurrence in other regions (14). Radiofrequency ablation is also effective and may be safely applied to retroperitoneal metastatic HCC lymph nodes (15). However, the majority of extrahepatic lymph node metastases of HCC are multiple and are not suitable for resection or radiofrequency ablation, as was the case with the present patient.

$\mathrm{HCC}$ is known as a radiosensitive tumor, and an increasing number of reports underline the efficacy of radiotherapy in the management of HCC (16-18); however, the application of radiotherapy in patients with $\mathrm{HCC}$ is limited due to the poor radiation tolerance of the normal liver to local control doses and the varied locations of the tumors. Recent improvements 
in radiation therapy delivery techniques have provided novel tools to treat patients with extrahepatic metastasis. Patients with intact liver function and without associated symptoms were found to have the most favorable prognosis out of all patients undergoing radiotherapy for lymph node metastasis from HCC (19). In a previous study, a major response to a radiation dose of $\geq 45$ Gy was observed, with a dose-response relationship determined for local control radiotherapy (20). In the present case, following the administration of 20 Gy radiation, the patient presented with a decrease in platelet count, which indicated radiation intolerance, despite relief of the symptom of pain following treatment. Thus, stereotactic body radiation therapy should be applied under strict conditions with the expertise of radiation oncology departments.

Sorafenib has also been shown to be effective in the treatment of patients with advanced or metastatic HCC $(21,22)$; however, it is only indicated for patients with well-preserved liver function (Child-Pugh A class) and advanced stage tumors (Barcelona Clinic Liver Cancer C) or tumors that progress upon locoregional treatment $(23,24)$. Despite well-preserved liver function, the present patient refused to receive sorafenib therapy on cost grounds.

In conclusion, the treatment options for extrahepatic metastasis of HCC are limited. The provision of careful follow-up and the control of extrahepatic recurrence following treatment are important for improving the quality of life and prognosis of HCC patients with extrahepatic metastases. Further studies are required to develop standard treatments that achieve this, including systemic adjuvant chemotherapy and radiotherapy.

\section{References}

1. Siegel R, Ma J, Zou Z and Jemal A: Cancer statistics, 2014. CA Cancer J Clin 64: 9-29, 2014.

2. Kanda M, Tateishi R, Yoshida H, Sato T, Masuzaki R, Ohki T, Imamura J, Goto T, Yoshida H, Hamamura K, et al: Extrahepatic metastasis of hepatocellular carcinoma: Incidence and risk factors. Liver Int 28: 1256-1263, 2008.

3. Gluer AM, Cocco N, Laurence JM, Johnston ES, Hollands MJ, Pleass HC, Richardson AJ and Lam VW: Systematic review of actual 10-year survival following resection for hepatocellular carcinoma. HPB (Oxford) 14: 285-290, 2012

4. Tanaka K, Shimada H, Matsuo K, Takeda K, Nagano Y and Togo S: Clinical features of hepatocellular carcinoma developing extrahepatic recurrences after curative resection. World J Surg 32: 1738-1747, 2008.

5. El-Serag HB: Hepatocellular carcinoma. N Engl J Med 365: 1118-1127, 2011.

6. Yang Y, Nagano H, Ota H, Morimoto O, Nakamura M, Wada $\mathrm{H}$, Noda T, Damdinsuren B, Marubashi S, Miyamoto A, et al: Patterns and clinicopathologic features of extrahepatic recurrence of hepatocellular carcinoma after curative resection. Surgery 141: 196-202, 2007.

7. Yuen MF, Ahn SH, Chen DS, Chen PJ, Dusheiko GM, Hou JL, Maddrey WC, Mizokami M, Seto WK, Zoulim F and Lai CL: Chronic hepatitis B virus infection: Disease revisit and management recommendations. J Clin Gastroenterol 50: 286-294, 2016.

8. Suzumura K, Hirano T, Kuroda N, Iimuro Y,Okada T, Hashimoto M, Hasegawa S and Fujimoto J: Solitary mediastinal metastasis of hepatocellular carcinoma treated by video-assisted thoracic surgery: Report of a case. Gen Thorac Cardiovasc Surg 61: 651-654, 2013.
9. Hung JJ, Lin SC and Hsu WH: Pancoast syndrome caused by metastasis to the superior mediastinum of hepatocellular carcinoma. Thorac Cardiovasc Surg 55: 463-465, 2007.

10. Chen CC, Yeh HZ, Chang CS, Ko CW, Lien HC, Wu CY and Hung SW: Transarterial embolization of metastatic mediastinal hepatocellular carcinoma. World J Gastroenterol 19: 3512-3516, 2013.

11. Oh SY, Seo KW, Jegal Y, Ahn JJ, Min YJ, Park CR and Hwang JC: Hemothorax caused by spontaneous rupture of a metastatic mediastinal lymph node in hepatocellular carcinoma: A case report. Korean J Intern Med 28: 622-625, 2013.

12. Xiaohong S, Huikai L, Feng W, Ti Z, Yunlong C and Qiang L: Clinical significance of lymph node metastasis in patients undergoing partial hepatectomy for hepatocellular carcinoma. World J Surg 34: 1028-1033, 2010.

13. Amini N, Ejaz A, Spolverato G, Maithel SK, Kim Y and Pawlik TM: Management of lymph nodes during resection of hepatocellular carcinoma and intrahepatic cholangiocarcinoma: A systematic review. J Gastrointest Surg 18: 2136-2148, 2014.

14. Ueda J, Yoshida H, Mamada Y, Taniai N, Mineta S, Yoshioka M, Kawano Y, Shimizu T, Hara E, Kawamoto C, et al: Surgical resection of a solitary para-aortic lymph node metastasis from hepatocellular carcinoma. World J Gastroenterol 18: 3027-3031, 2012.

15. Gao F, Gu Y, Huang J, Zhao M and Wu P: Radiofrequency ablation of retroperitoneal metastatic lymph nodes from hepatocellular carcinoma. Acad Radiol 19: 1035-1040, 2012.

16. Jang WI, Kim MS, Bae SH, Cho CK, Yoo HJ, Seo YS, Kang JK, Kim SY, Lee DH, Han CJ, et al: High-dose stereotactic body radiotherapy correlates increased local control and overall survival in patients with inoperable hepatocellular carcinoma. Radiat Oncol 8: 250, 2013.

17. Kwon JH, Bae SH, Kim JY, Choi BO, Jang HS, Jang JW, Choi JY, Yoon SK and Chung KW: Long-term effect of stereotactic body radiation therapy for primary hepatocellular carcinoma ineligible for local ablation therapy or surgical resection. Stereotactic radiotherapy for liver cancer. BMC Cancer 10: 475, 2010.

18. Huang WY, Jen YM, Lee MS, Chang LP, Chen CM, Ko KH, Lin KT, Lin JC, Chao HL, Lin CS, et al: Stereotactic body radiation therapy in recurrent hepatocellular carcinoma. Int J Radiat Oncol Biol Phys 84: 355-361, 2012.

19. Kim K, Chie EK, Kim W, Kim YJ, Yoon JH, Lee HS and Ha SW: Absence of symptom and intact liver function are positive prognosticators for patients undergoing radiotherapy for lymph node metastasis from hepatocellular carcinoma. Int J Radiat Oncol Biol Phys 78: 729-734, 2010.

20. Yoon SM, Kim JH, Choi EK, Ahn SD, Lee SW, Yi BY, Chung YW, Lee YS and Seo DJ: Radioresponse of hepatocellular carcinoma-treatment of lymph node metastasis. Cancer Res Treat 36: 79-84, 2004.

21. Llovet JM, Ricci S, Mazzaferro V, Hilgard P, Gane E, Blanc JF, de Oliveira AC, Santoro A, Raoul JL, Forner A, et al: Sorafenib in advanced hepatocellular carcinoma. N Engl J Med 359: 378-390, 2008.

22. Bruix J, Raoul JL, Sherman M, Mazzaferro V, Bolondi L, Craxi A, Galle PR, Santoro A, Beaugrand M, Sangiovanni A, et al: Efficacy and safety of sorafenib in patients with advanced hepatocellular carcinoma: Subanalyses of a phase III trial. J Hepatol 57: 821-829, 2012.

23. Raoul JL, Bruix J, Greten TF, Sherman M, Mazzaferro V, Hilgard P, Scherubl H, Scheulen ME, Germanidis G, Dominguez $\mathrm{S}$, et al: Relationship between baseline hepatic status and outcome, and effect of sorafenib on liver function: SHARP trial subanalyses. J Hepatol 56: 1080-1088, 2012.

24. Abou-Alfa GK, Amadori D, Santoro A, Figer A, De Greve J, Lathia C, Voliotis D, Anderson S, Moscovici M and Ricci S: Safety and efficacy of sorafenib in patients with hepatocellular carcinoma (HCC) and Child-Pugh A versus B cirrhosis. Gastrointest Cancer Res 4: 40-44, 2011. 